\title{
الإشهار في وسائل الإعلام الوطنية وإثكالية الخدمة العمومية
}

\author{
د/ إيكوفان شفيق \\ كلية الحقوق معنق \\ جامعة مولود معمري

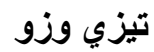

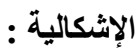

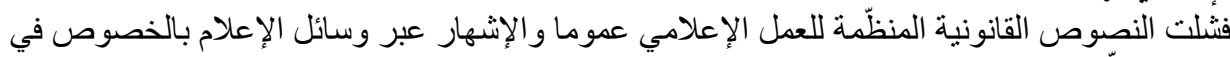

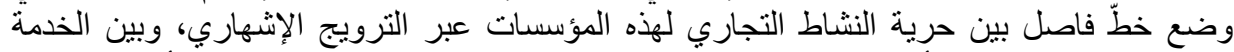

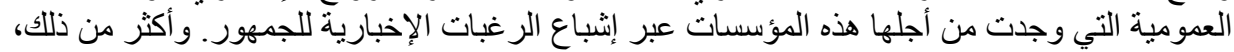

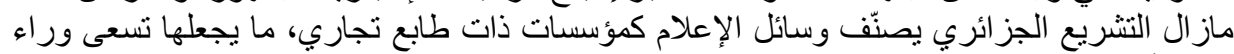

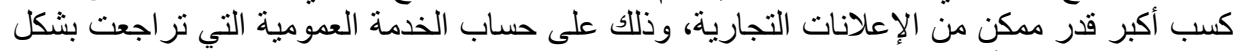

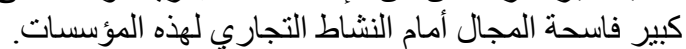

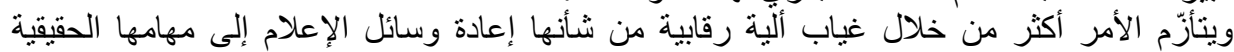

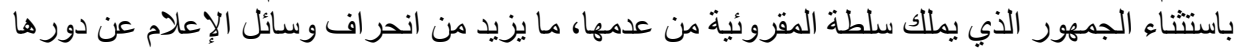

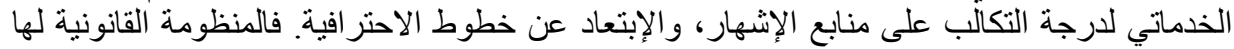

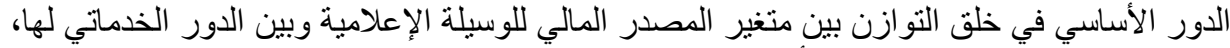

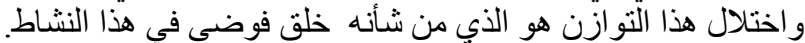

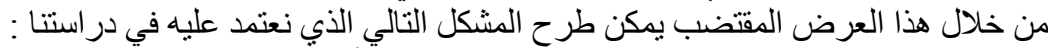

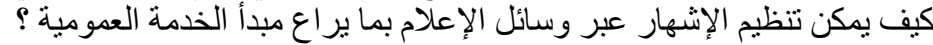

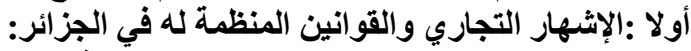

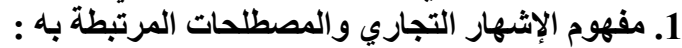

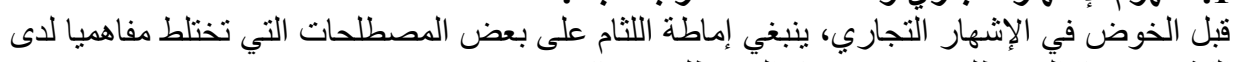

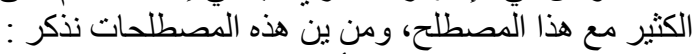
ــ الإعلان : الإعلان هو من أقدم المصطلحات استخداما في المجال الإن الإعلامي مقارنة بقية المصطلحات،

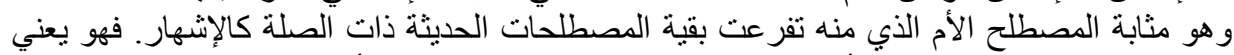

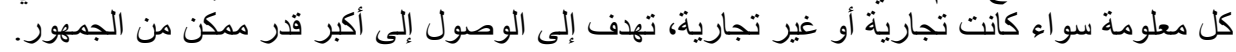

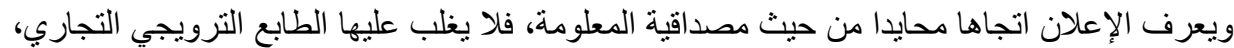

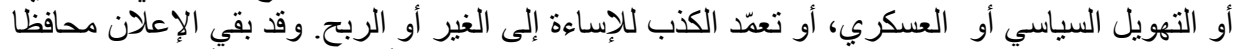

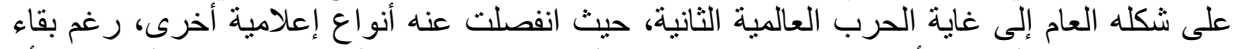

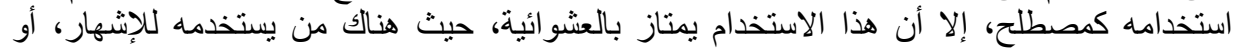

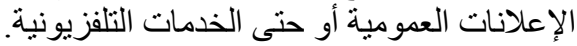

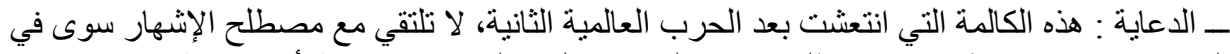

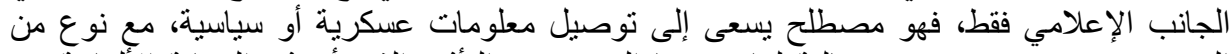

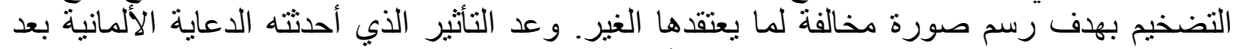

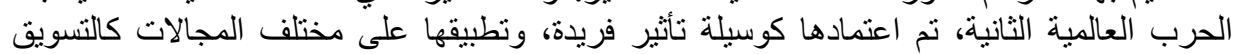

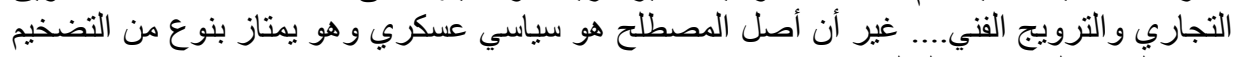
بهدف التحكم النفسي في المتلقي.

(C) جامعة الإخوة منتوري قسنطينة، الجزائر 


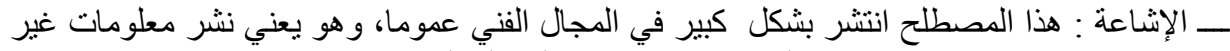

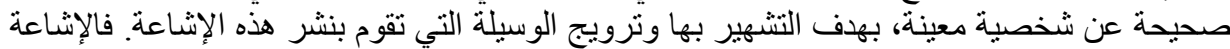

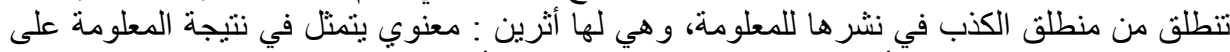

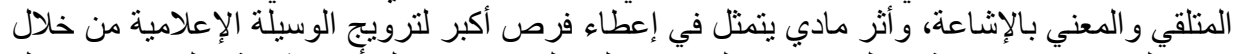

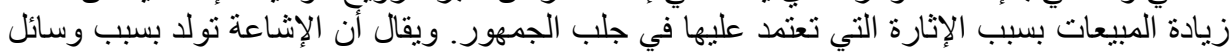

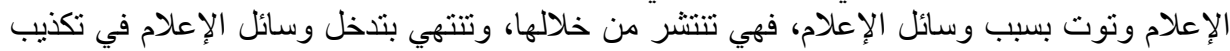

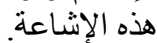
- الإشهار : هذا المصطلح هو الأقرب من مصطلح التعريف والترويج، وقد اكتسى الطابع التجاري

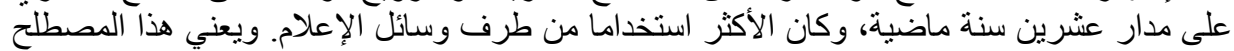

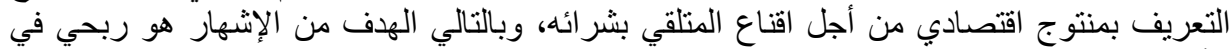

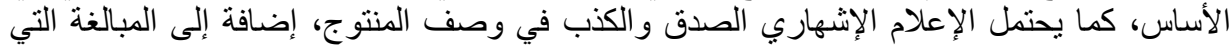

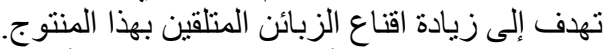

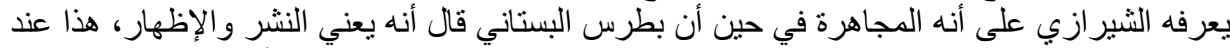

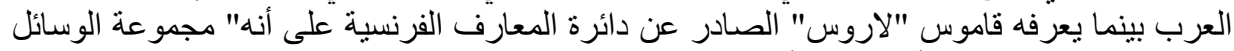

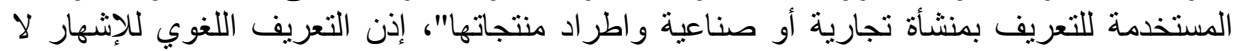
يتعدى الثرح اللغوي للفظ الإشهار أُما في التعريف الغربي الوارد في قاموس"لارئلاروس" فهو في الحقيقة أكثر شمولية من الدفهوم الحقيقي،

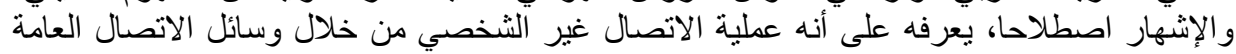

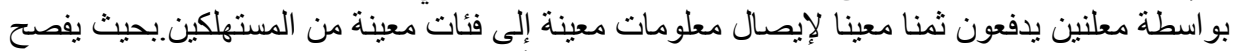

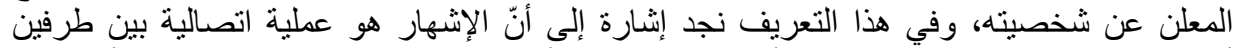

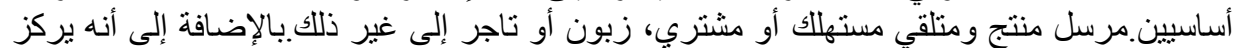

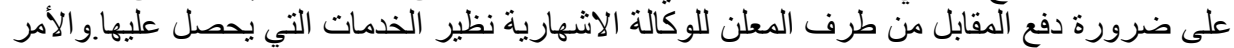

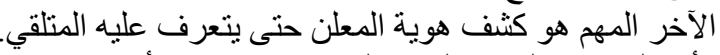

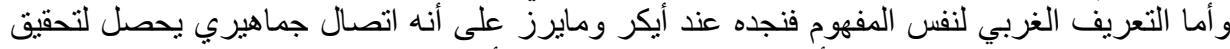

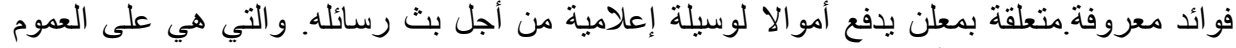

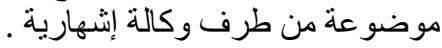
و هنا يظهر جليا الاتفاق الحاصل بين الفكر العربي و الغربي.فكلاهما يركز على على الطابع الجماهيري

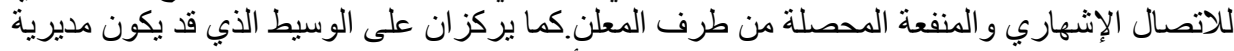

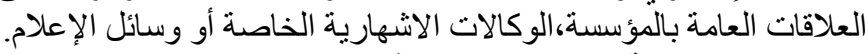

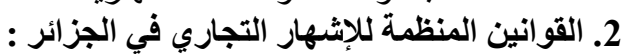

أ. الإثهار في الفترة بين لمين الإنها 1967 ـ 1989

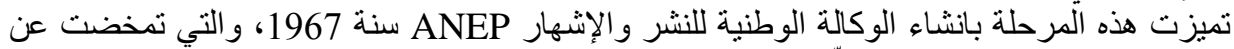

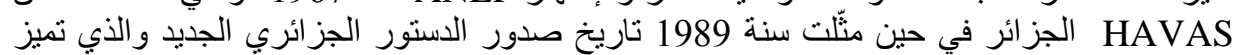

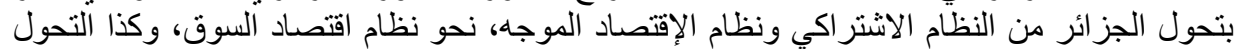

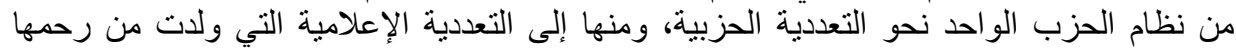

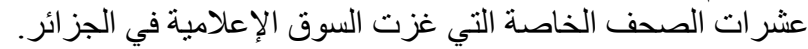

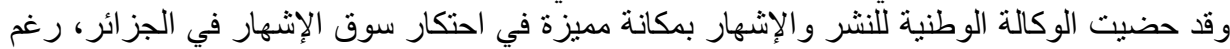

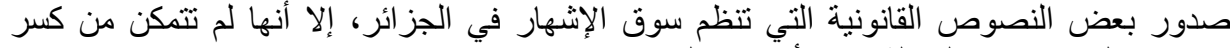

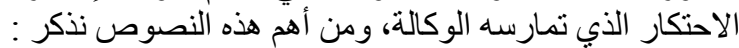

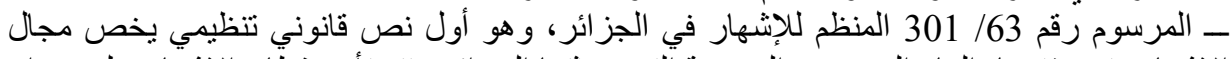

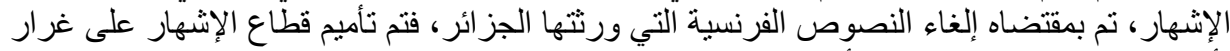
تأميم بقية القطاعات الاستر اتجيةُأنذاكلك. 
ـــ المرسوم رقم 67/ 279 المتضمن انشاء الوكالة الوطنية للنشر و الإتشهار : تز امن هذا القانون مع رسم

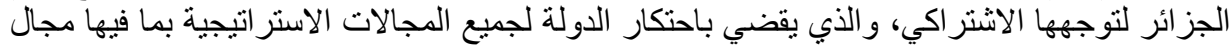

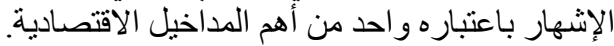

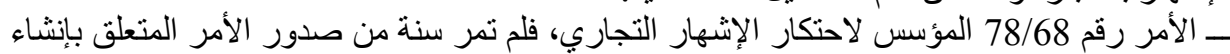

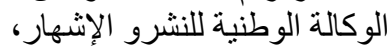
صدر أمر يقر بتأسيس الإحتكار للإشهار منمثلا في الأمر رقم 68/78 ويسند حق الإحتكار

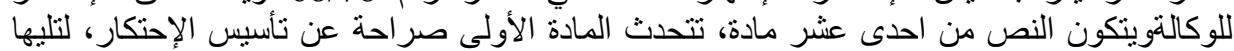

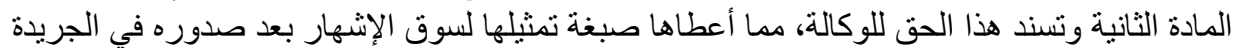

الرسمية مباثر

الأمر 69/71 المتضمن تأسيس الاحتكار الخاص بالاشهار التجاري

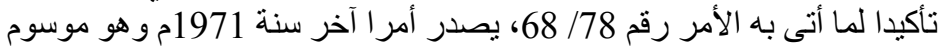

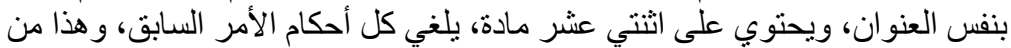

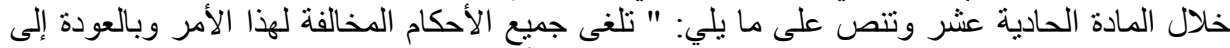

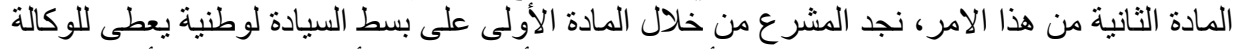

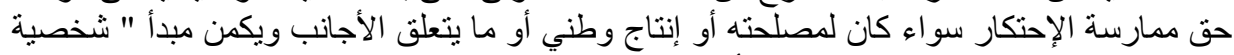

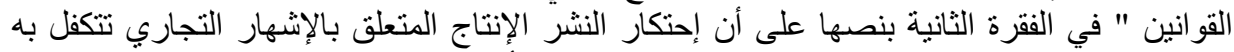

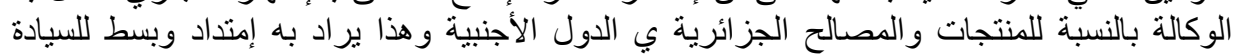

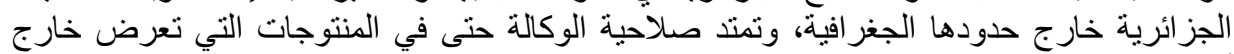

أر اضيها مادامت منتوجات جزائر الئرية.

المرسوم 86/283 المتضمن إعادة تنظيم الوكالة الوطنية للنشر والاشهار :

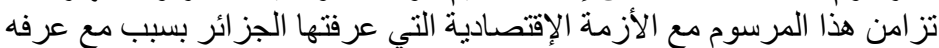
الإنخفاض الثنديد لأسعار النفط في الأسواق العالمية وفقا للعلاقة بين طرفي الإشهار

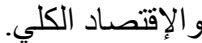

وقد اعتبر المرسوم الوكالة ذات طابع إقتصادي وصبغة إجتماعية وثقافية وذلك التكاري

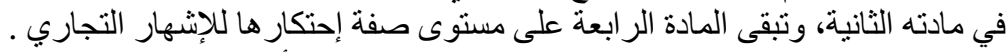

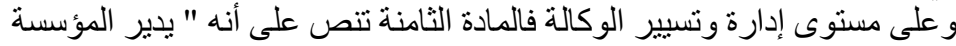

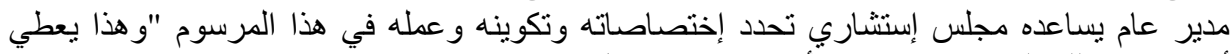

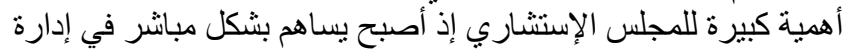

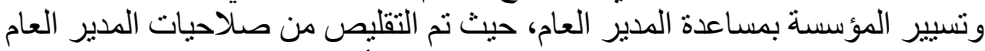

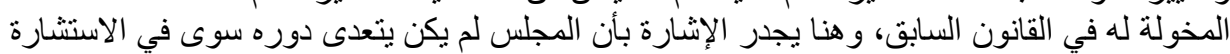

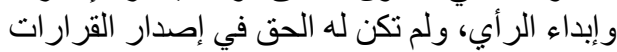

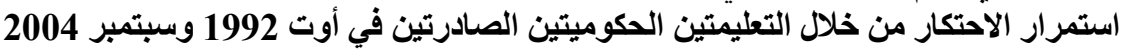

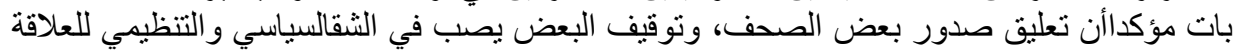

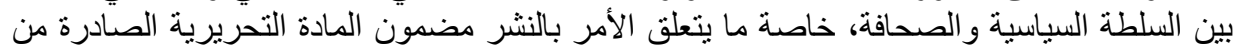

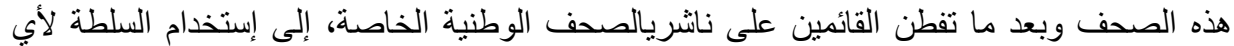

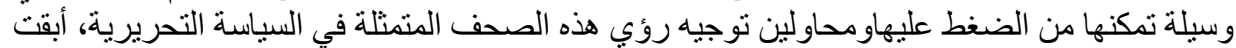

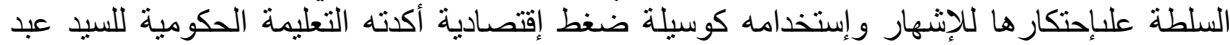

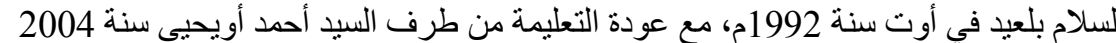
ولأن السلطة كانت مدركة بأن التحول في التوجه الإقتصاديسينعكس على على استقلالية وأداء الصحافيلة الصافة

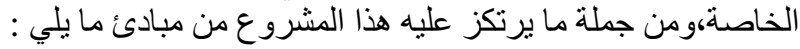

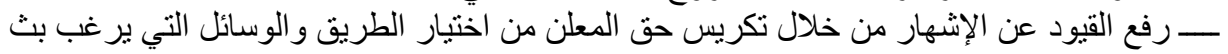
إثهار اته بو اسطتها وفي نفس الوقت تمكين من لهم الإمكانيات من الاستثمار في هذا النشاط من خلال 


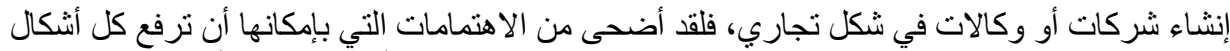

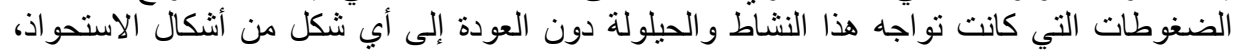

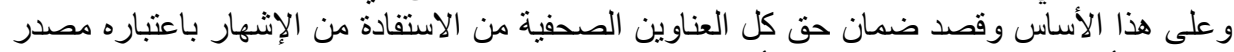

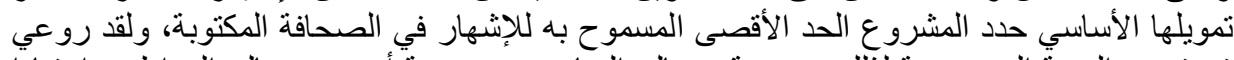

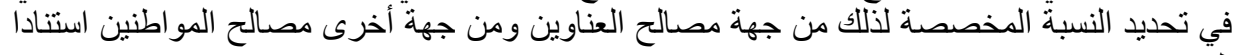
إلى حقهم في الإعلام

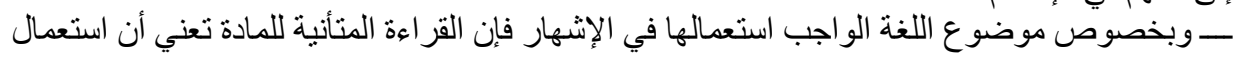

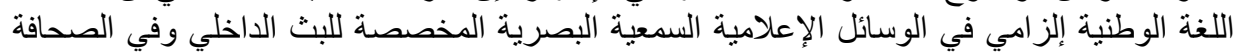

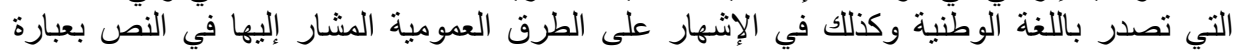

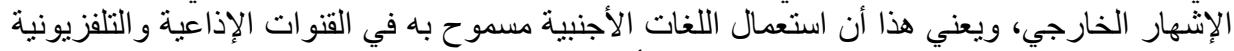

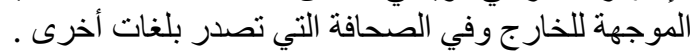

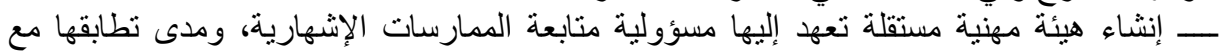

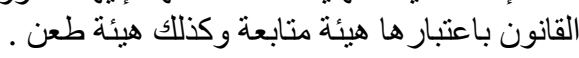

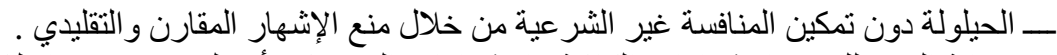

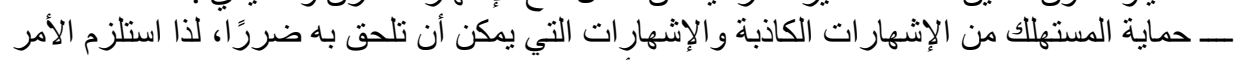

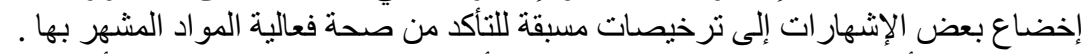

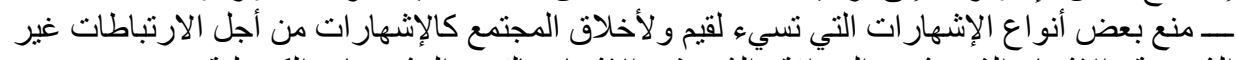

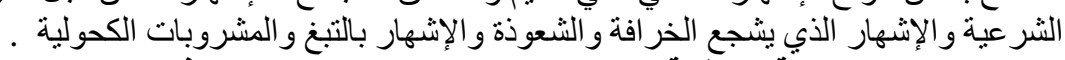

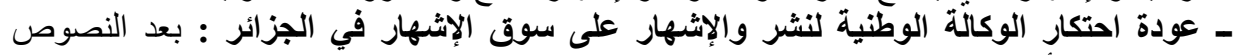

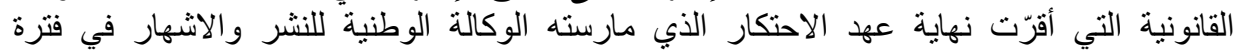

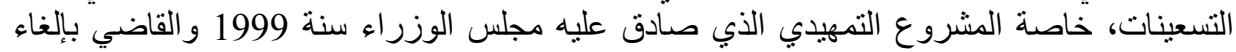

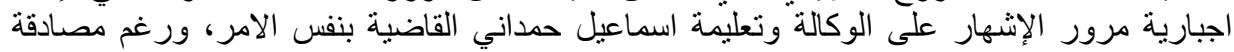

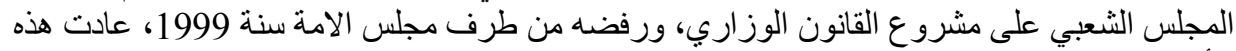

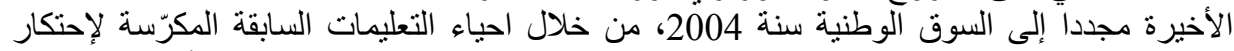

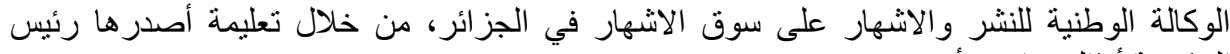

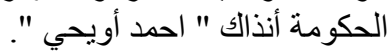

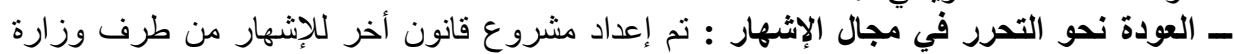

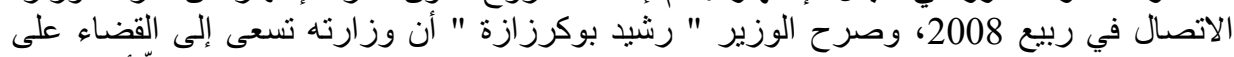

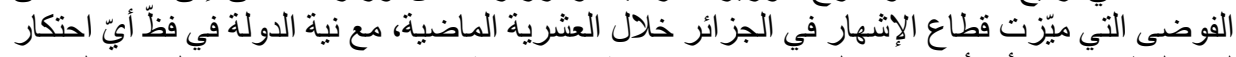

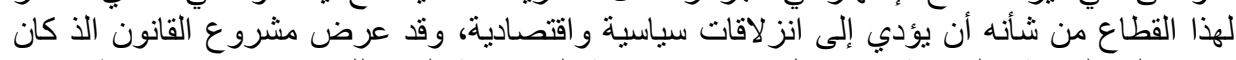

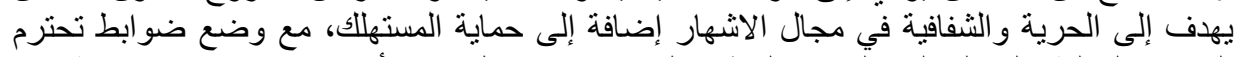

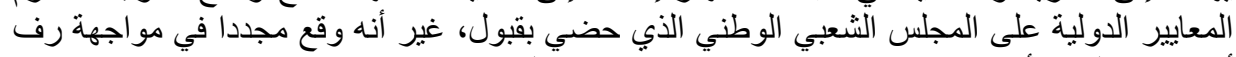

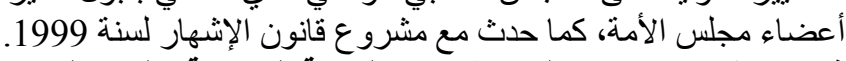

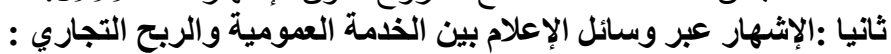

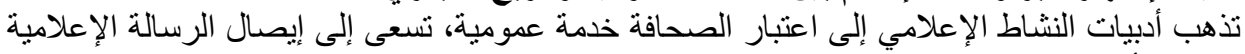

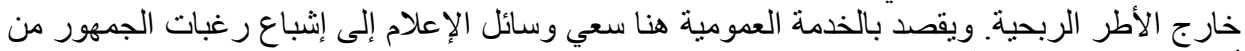

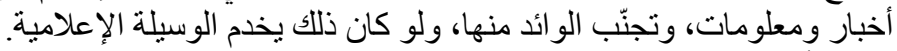

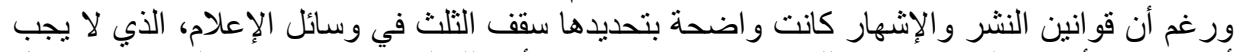

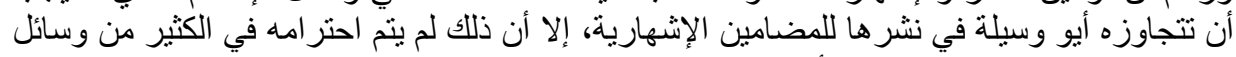

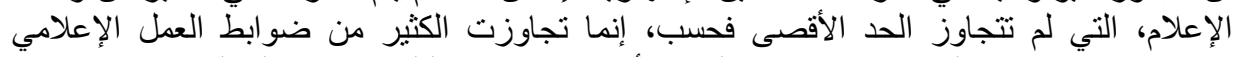

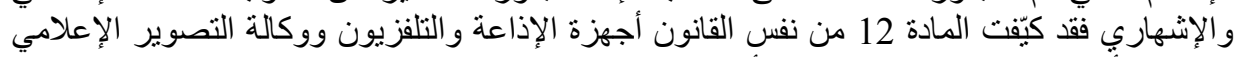
ووكالة الأنباء التابعة للقطاع العام على أنها مؤسسات عمومية ذات الفات طابع صناعي وتجاري. و وهي بذللك 


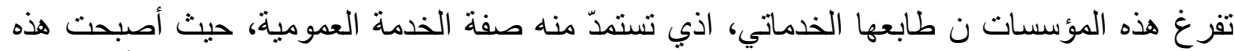

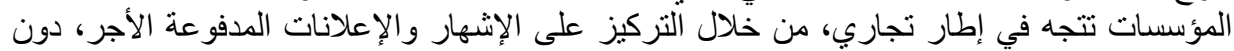

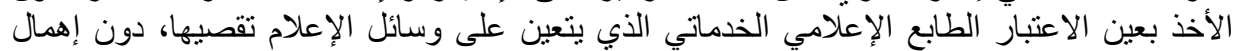

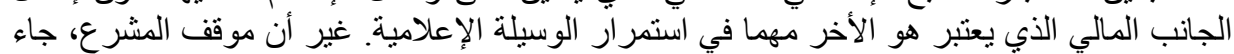

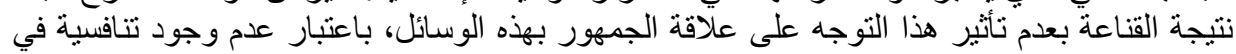

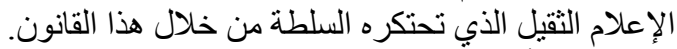

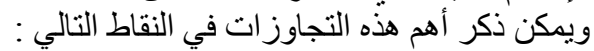

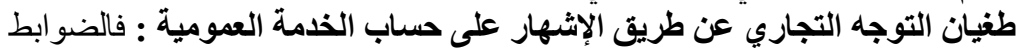

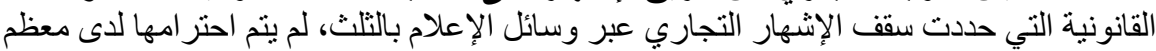

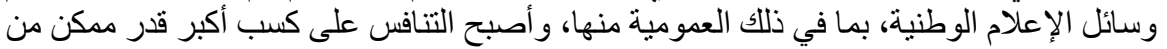

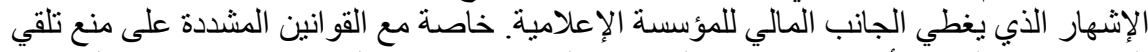

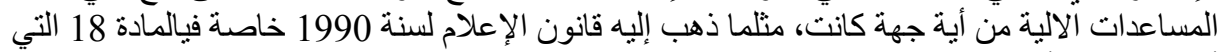

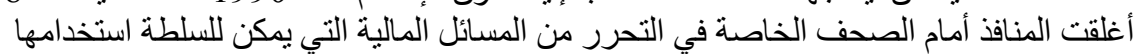

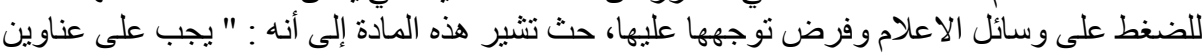

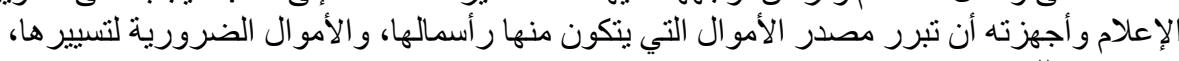

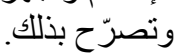

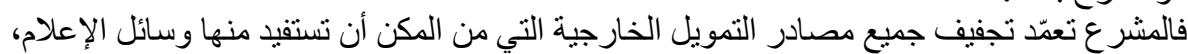

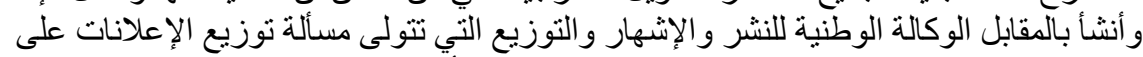

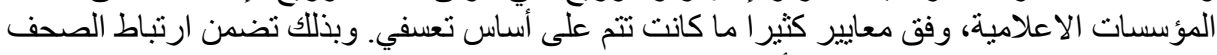

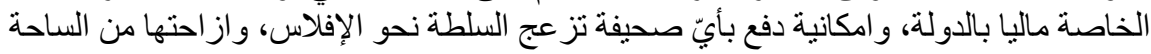

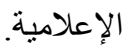

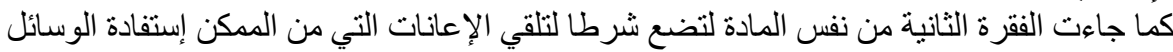

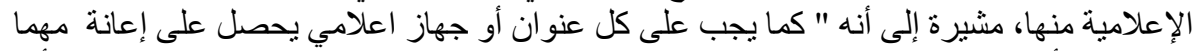

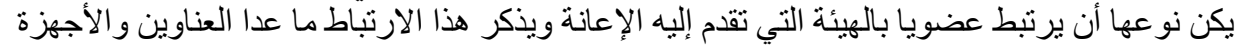

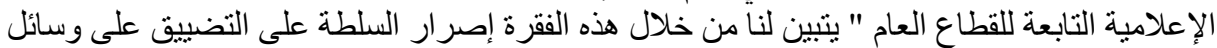

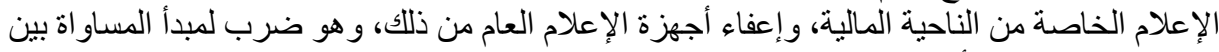

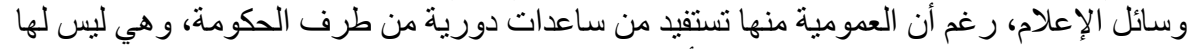

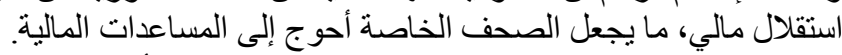

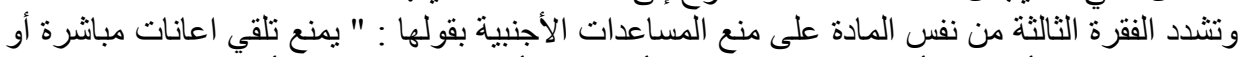

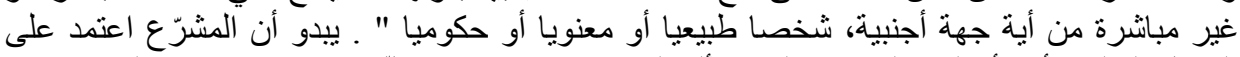

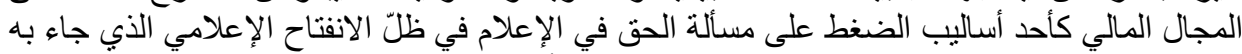

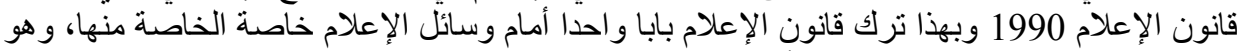

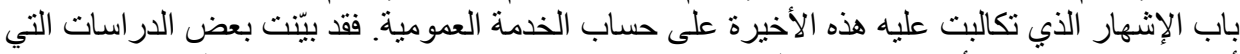

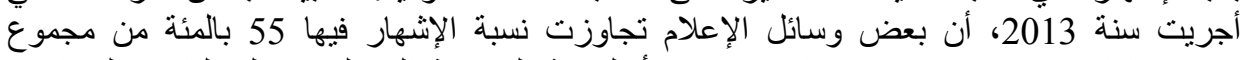

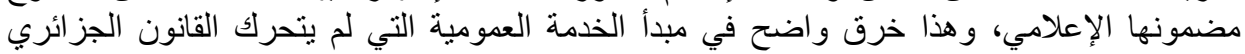

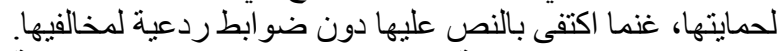
2.

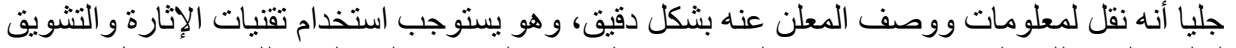

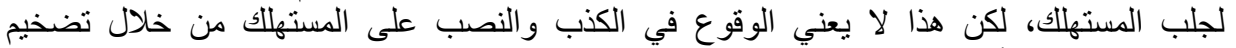
خصائص المنتوج أو تزييف حقائقه.

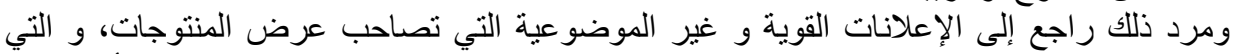
تمارس ضغطا قويا على إرادة المستهلك، وتحجب على عنه المعطيات الحقيقية عن جوهر المادة أو الخدمة 
و هذا لا ينفي وجود إعلانات ليس فيها خطورة على سلامة المستهلك، إلا أنها قليلة مقارنة مع التي التي

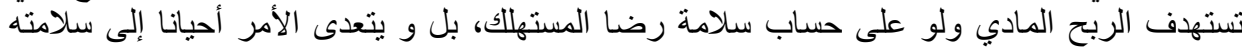

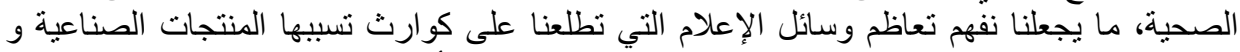

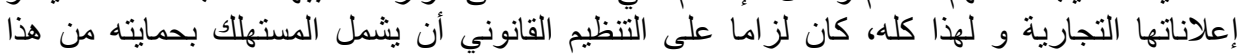

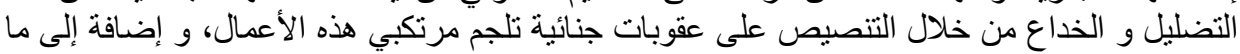

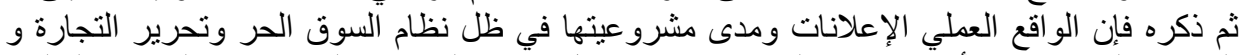

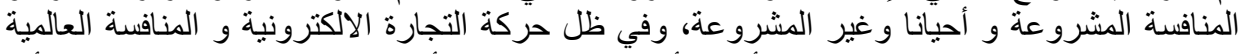

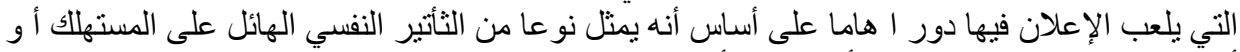

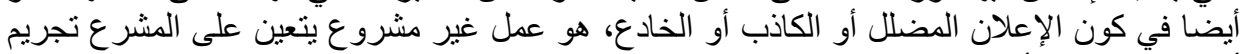

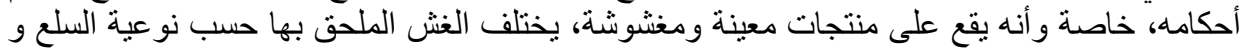

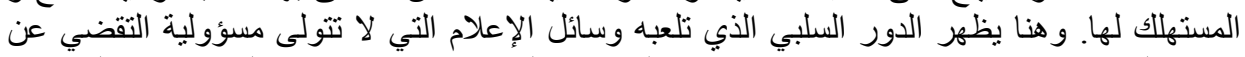

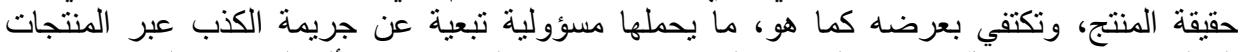
المعلنة، خاصة في ظلّ سكوت المشرع الجز ائري عن هذه النقطة في مسألة العقوبات المككن تطبيقها على مر تكبي هذه الكخالفة. 3.

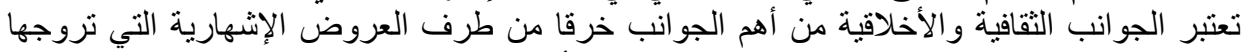

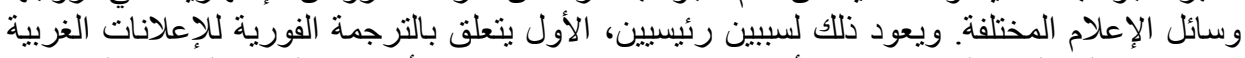

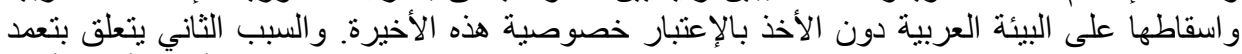

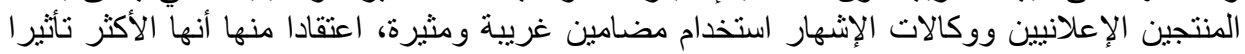
على المستهلاك.

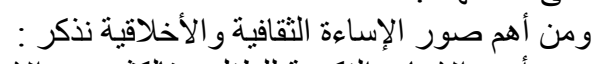

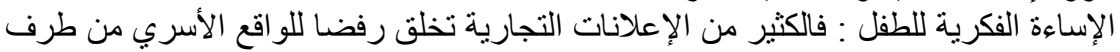

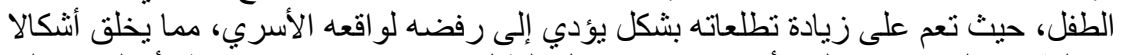

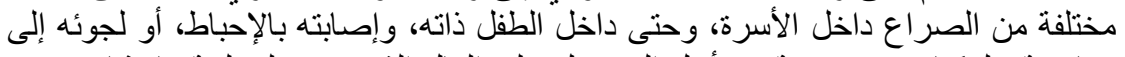

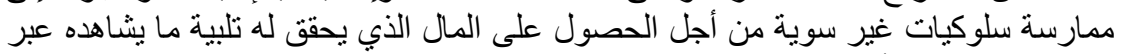

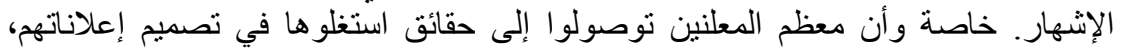

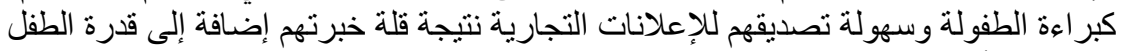

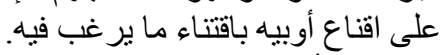

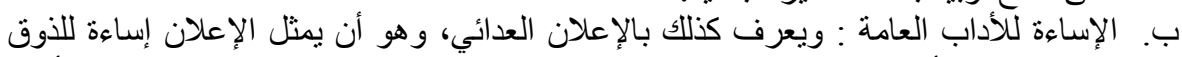

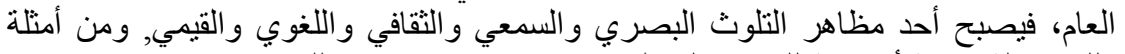

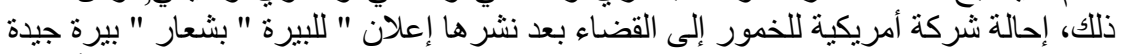

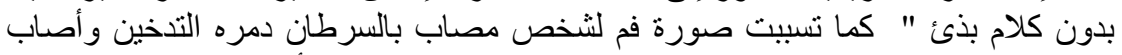
اسنانه بالتعفن في موجة من الثكاوي، حيث نلقى مكتب الإعلان الأستر الي 170 شُكوى في هذا الصدد.

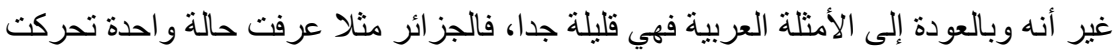

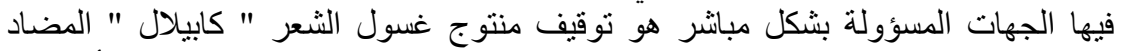

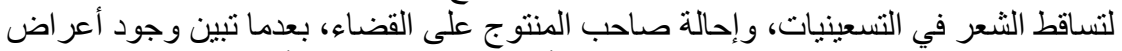

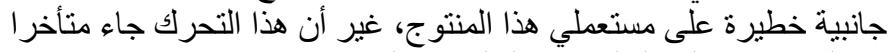

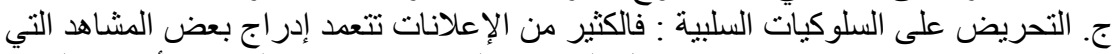

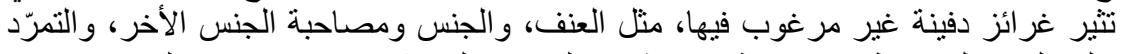

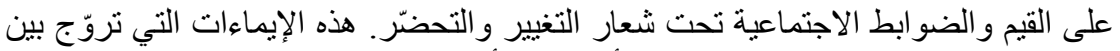
الثباب والاطفال تبدوا غير مؤثرة، إلا أنها ترك أنثار الذب خطيرة على المستوى المتوسط 


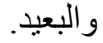

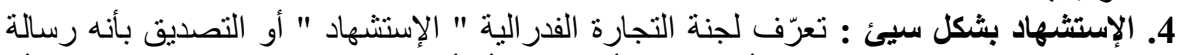

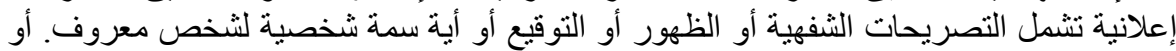

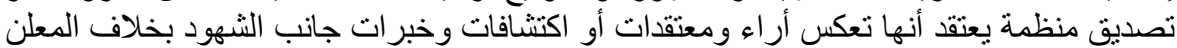

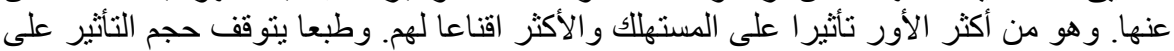

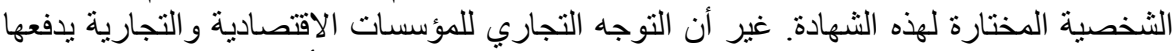

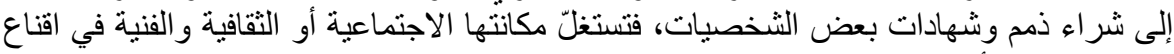

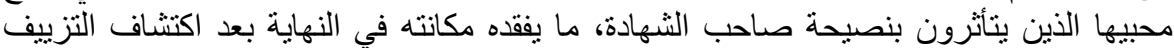

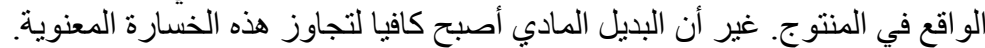

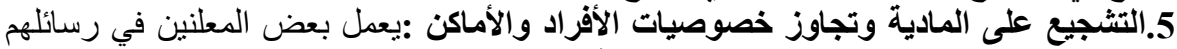

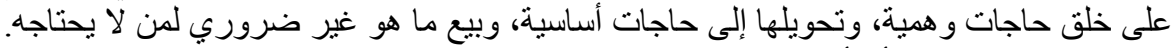

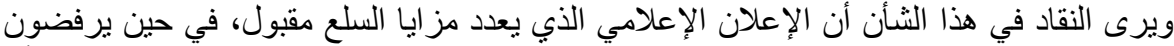

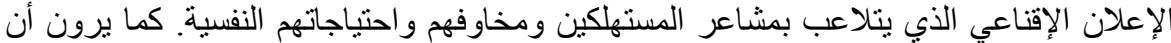

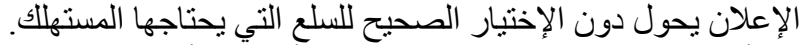

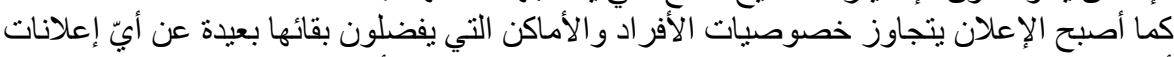

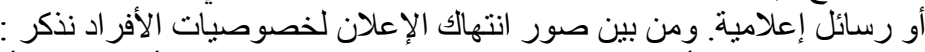

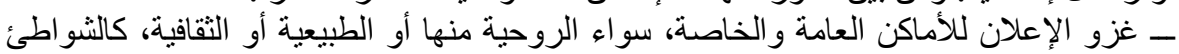
و الغابات، ودور الإعلان لـون و العبادة...

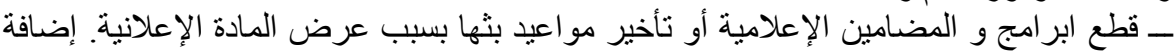
إلى طغيان المادة الإعلانية عن المادة الإعلامية الخبانية الخبرية.

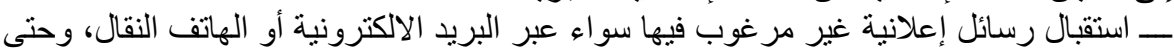

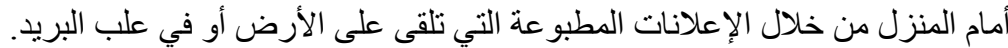

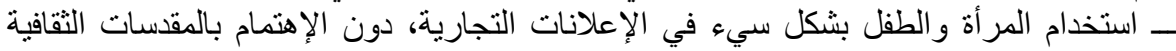
و القيمية، ما يحول هذه الفئة إلى سلع تجارية وسلَ وسلع رخيصة.

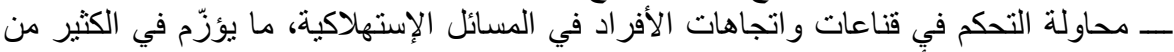

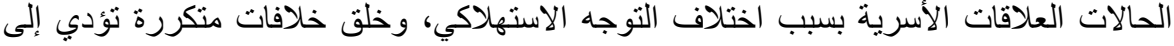
ت تعكبر صفو العائلة.

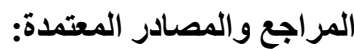

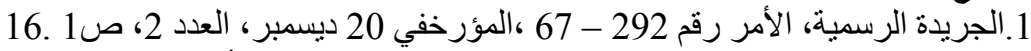

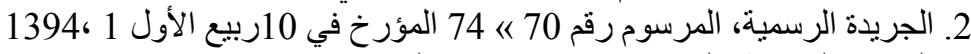

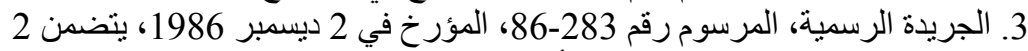

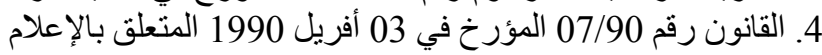

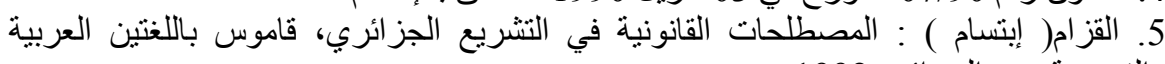

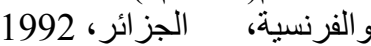
6. حسن نيازي الصيفي، أخلاقيات الإعلان في الفضائيات العربية، دار الفجر للنشر والتوزيع،

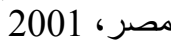

7. محمد حسن العامري، الإعلان وحماية المستهلك، العربي للنشر و التوزيع، العراق، الطبعة1، 